\title{
Effects of Health-Related Knowledge and Aerobic Exercise on Lower Secondary School Students' Obesity Awareness and Physical Activity Levels
}

\section{Gizem Akgül Ertan ${ }^{1}$ Funda Coşkun Özyol ${ }^{2}$}

${ }^{1}$ Sehit Kemal Görgülü Lower-Secondary School, Van, Turkey.

Email:gizem_kayak@hotmail.com Tel: +904324445065

${ }^{2}$ Van Yüzüncü Yil University, The School of Physical Education and Sports, Van, Turkey.

Email:fcoskun@yyu.edu.tr.Tel:+904322251702

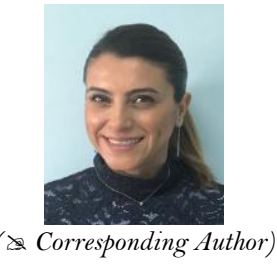

( Corresponding Author)

\section{Abstract}

The objective of this study was to examine the effects of health-related knowledge and aerobic exercise on lower secondary school students' obesity awareness and physical activity levels. A total of 50 obese and 20 normal-weight female students, ranging in age from 12-14 (mean 12.10 \pm 1.7 ), participated in the study. Obesity awareness was determined using the Obesity Awareness Scale, which also incorporates awareness of nutrition and physical activity. Physical activity levels were determined using a pedometer. The participants were divided into one obese experimental group and 2 control groups, obese and normal weight. The obese experimental group received instruction in health and nutrition and followed an aerobic exercise program, while the control groups received no such instruction and did not participate in an exercise program. The health education program was conducted once a week, while the aerobic exercise program was performed three times a week, with each session lasting 45-60 minutes. At the conclusion of the study, the obesity awareness, nutrition awareness, and physical activity awareness scores of the students in the obese experimental group increased significantly compared to those of the obese control and normal control groups. Similarly, the physical activity levels of the students in the obese control group increased with respect to those of the obese and normal-weight control groups. These findings suggest that health-related knowledge and aerobic exercise were effective in increasing obesity awareness and the physical activity levels of lower secondary school students.

Keywords: Secondary school student, Health-related knowledge, Obesity awareness, Physical activity, Aerobic exercise, Pedometer

Citation | Gizem Akgül Ertan; Funda Coşkun Özyol (2020). Effects of Health-Related Knowledge and Aerobic Exercise on Lower Secondary School Students' Obesity Awareness and Physical Activity Levels. Asian Journal of Education and Training, 6(2): 297303.

History:

Received: 11 February 2020

Revised: 16 March 2020

Accepted: 23 April 2020

Published: 21 May 2020

Licensed: This work is licensed under a Creative Commons

Attribution 3.0 License $(\mathbf{c c})$ E

Publisher: Asian Online Journal Publishing Group
Acknowledgement: Both authors contributed to the conception and design of the study.

Funding: This study was supported by the Research Fund of Van Yüzüncü Yll University in Turkey with Project Number: SYL-2018-7383.

Competing Interests: The authors declare that they have no conflict of interests.

Transparency: The authors confirm that the manuscript is an honest, accurate, and transparent account of the study was reported; that no vital features of the study have been omitted; and that any discrepancies from the study as planned have been explained.

Ethical: This study follows all ethical practices during writing.

\section{Contents}

1. Introduction

2. Method

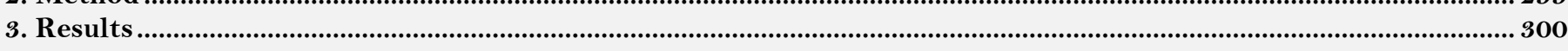

4. Discussion ......... 301

References. 


\section{Contribution of this paper to the literature}

While the studies so far have focused on the prevalence of obesity in children and adolescents, it has been observed that the studies on the effects of the diet and exercise related programs implemented within the scope of the experimental model on obesity are limited. Our research seeks to contribute to fill this gap in the literature by examining the effects of health-related knowledge and aerobic exercise on lower secondary school students' obesity awareness and physical activity levels.

\section{Introduction}

Overweight or obesity is defined as abnormal or excessive fat accumulation that negatively affects health. According to the World Health Organization (WHO), in 2016, 1.9 billion adults aged 18 and over were reported to be overweight, over 650 million of whom were obese (World Health Organization (WHO), 2020a). The WHO data also showed that, globally, 39\% of adults over the age of 18 were overweight and $13 \%$ were obese, 40 million children under the age of 5 were overweight or obese in 2018, and 340 million children and adolescents aged 5-19 were overweight or obese. Overweight and obesity in adults stimulate non-communicable diseases such as cardiovascular diseases, diabetes, musculoskeletal disorders, and some types of cancer. In children, overweight and obesity increases the risk of fractures, hypertension, and preliminary symptoms of cardiovascular disorders, causes insulin resistance, and presents psychological issues (World Health Organization (WHO), 2020a). In order to avoid or minimize the risk of developing such health problems, World Health Organization (WHO) (2020a) recommended healthy eating and regular exercise. Research has shown that inadequate physical activity is one of ten risk factors that threaten human life. Studies showed that in $2016,32 \%$ of women over the age of 18 and $23 \%$ of men were physically inactive worldwide, while data from 2010 revealed that $81 \%$ of adolescents between the ages of 11 and 17 attending school did not sufficiently engage in physical activity (World Health Organization (WHO), 2020b). Childhood obesity is caused by a long-term imbalance between energy intake and energy expenditure. The primary causes of childhood obesity include physical inactivity associated with mental issues, lack of physical fitness, the risk of developing cardiovascular disease, and compromised bone health (Ozturk et al., 2009). Studies observing the development of Turkish children and adolescents at the national level are limited, but such studies have been carried out at the local level. Studies showed that the percentage of individuals who are overweight and obese in Turkey gradually increases, and childhood obesity is $6.5 \%$, and this rate rises to $14.3 \%$ in overweight children (Turkish Ministry of Health, 2011). Thus, the period of childhood/adolescence is of critical importance for the adoption of healthy lifestyle habits, as unhealthy habits acquired at a young age, such as a sedentary lifestyle and/or poor nutrition, are difficult to change when older (Akyol, Boyraz, \& Aysoy, 2013).

The World Health Organization (WHO) (2020c) advises physical activity for people of various ages to prevent obesity. The physical activity recommendation for children and adolescents between 5-17 years of age involves at least 60 minutes of moderate to high-intensity aerobic activity, with physical activity exceeding 60 minutes constituting an extra benefit. In a study conducted to determine the physical activity levels of children and adolescents, data from 1.6 million children and adolescents aged 11-17 were collected from 298 schools in 146 countries. The findings revealed that $84.7 \%$ of girls and $66.6 \%$ of boys were not physically active (Guthold, Stevens, Riley, \& Bull, 2020). In another study, Jurakic and Pedisic (2012) examining the physical activity levels in children and adolescents, found that between $2.4 \%$ and $39.3 \%$ of girls were insufficiently physically active, according to measurements taken using an accelerometer; the range based on the questionnaire results was $19.5 \%$ $95 \%$. These rates for boys varied between $2.6 \%-18.1 \%$ and $12.2 \%-89 \%$, respectively. In a review study incorporating the results of 131 studies from European countries, the physical activity levels of children and adolescents measured by accelerometer were examined, with the result that the participants in 35 studies met the recommended criteria for physical activity (Guinhouya, Samouda, \& De Beaufort, 2013). The World Health Organization has reported that $81.3 \%$ of female and male individuals in Turkey were physically inactive. In a study examining the physical activity levels of 11-12-year-old Turkish children, Kudaş, Ulkar, Erdoğan, and Cirçı (2005) found that $71 \%$ of the boys and $34 \%$ of the girls were physically active outside the classroom, while $94.6 \%$ of the boys and $17 \%$ of the girls were active during school hours. In another study, Urlu (2014) found that boys aged 1012 were more physically active than girls of the same age. Comparing the physical activity levels of high school and university students, Tunç and Işler (2007) revealed that high school students had higher levels of physical activity compared to university students.

One of the most common methods used to measure physical activity measurement is the pedometer, which was developed to count steps (Can, 2019). Various studies have been carried out at the international and national levels with the use of pedometers to determine the physical activity levels of children and adolescents. In one of these studies, Raustorp and Fröberg (2018) examined the physical activity levels of Swedish school children and adolescents between 2000 and 2017 using a pedometer. They found that the number of steps taken per week by $8-$ year-old girls in 2000 and 2017 did not differ significantly, but the physical activity levels of boys in the same age group increased by $8 \%$ over the same period. The physical activity levels of both girls and boys aged 11 decreased by $12 \%$ between 2000 and 2017 , while during the same period those of 14 -year-oldgirls and boys decreased by $24 \%$ and $30 \%$, respectively. In a study conducted in Tokyo, the physical activity levels of Japanese children and adolescents aged 6-18 were determined using pedometers. In that study, elementary and junior high school boys were found to have taken more steps compared to the girls, but there was no significant difference between the genders at the high school level. In addition, the number of steps taken decreased with increasing age and grade level, such that students were recorded taking the fewest number of steps in the final year of junior high school. Beets, Bornstein, Beighle, Cardinal, and Morgan (2010) compiled the findings obtained by studies on physical activity levels in 13 different countries, finding that young girls and boys living in Europe and countries located in the Western Pacific region took more steps than those living in America and Canada. In a study examining the physical activity levels of Turkish children and adolescents based on pedometer readings, Saygin and Ceylan (2017) found that secondary school boys were more active than their female counterparts. However, the female high school students were revealed to be more active than the male students. Bilgin, Bulca, and Demirhan (2020) 
recorded the number of steps taken by students in the $7^{\text {th }}$ grade from the moment they awoke until bedtime, finding that students took more steps on the days they had physical education classes than on days without. Saygin and Bayrakdar (2012) recorded the number of steps taken by primary school boys for two days during the week and one day on weekends; their physical activity levels were moderate based on the pedometer results. Demirci (2017) measured the activity levels of children aged 11-13 years who participate in sports outside of school and found that the number of steps taken by boys normally reached the recommended level, and even exceeded it on days with sports activities. The same study also revealed, however, that the number of steps taken by girls reached the recommended level only on the days of sports activities. Thus, sports activities were considered beneficial for increasing the physical activity levels of both girls and boys.

Physical activity and proper nutrition have been scientifically demonstrated to play important roles in the prevention of obesity. In a review study examining the effects of physical activity on obesity, especially in experimental models, physical activity was revealed to contribute to significant weight loss (Collins et al., 2011). School children participating in healthy nutrition and physical activity programs were found to lose weight compared to their peers who did not participate in the programs (Katz, O'Connell, Njike, Yeh, \& Nawaz, 2008). In a sample survey conducted in Turkey, adolescents at risk of obesity were provided with training to develop behaviors promoting positive health; the effects of this training on the participants' lifestyle behaviors and physical activity were then examined (Yesilfidan, 2016). The researcher concluded that the health-related behaviors of the participants were positively affected by the instruction they received. In Turkey, there has only been limited research on the prevention of obesity in children and adolescents through physical activity and health education. Therefore, we believe that instructing obese lower secondary school students on the benefits of physical activity and proper nutrition should have a positive effect. Therefore, the objective of this study was to examine the effects of health-related knowledge and participation in an aerobic exercise program on elementary school students' obesity awareness and physical activity levels.

\section{Method}

\subsection{Research Design}

In this study examining the effects of aerobic exercise and wellness training on obesity awareness and physical activity levels, the participants were administered pre and post-tests, and a randomized controlled experimental design was used.

\subsection{Participants}

The study participants were recruited from a local school during the 2018-2019 academic year and consisted of 75 female students (25 obese intervention, 25 obese control, 25 normal control) with a mean age of $12.10 \pm 1.7$ years (range $=12-14 \mathrm{yrs}$ ).

\subsection{Data Collection Instruments \\ 2.3.1. Obesity Awareness Scale}

The Obesity Awareness Scale used in the present study was developed by Allen (2011) to reveal individuals' awareness of obesity and was adapted for Turkish by Kafkas and Ozen (2014). The scale consists of 23 items and is divided into three subscales: obesity awareness ( 8 items), nutrition awareness ( 8 items), and physical activity awareness (5 items). It employs a 4-point Likert scale ranging from negative to positive responses; a high score corresponds to increased awareness. The internal consistency coefficient for the scale in its original form was $\alpha=$ .80 , while that of the Turkish version was $\alpha=.87$. In the current study, the Cronbach's alpha obtained for the scale as a whole was .91.

\subsubsection{Physical Activity Measures}

A pedometer was used to determine the physical activity levels of the experimental and control group students participating in this study. The pedometer (3D PM2000), which was distributed by the Turkish Ministry of Health, had a clock, 3D sensor, step counter, distance counter, calorie counter, 7-day memory, and target step adjustment features. Pedometer records were divided into weekday (Monday, Wednesday, and Friday) and weekend (Saturday and Sunday) categories. Students wore the pedometers 5 days per week for 12 weeks to determine their daily physical activity levels. On weekdays, the pedometers were placed on the children at 07.00 in the morning, before the start of school, and were removed at 12:30 p.m. after school had ended. On the weekends, the pedometers were put on as soon as the children awoke and removed before they went to sleep. Children and their parents were both informed that this device should be worn for the full day upon waking up in the morning and removed before going to bed at the end of the day, as well as before showering or swimming.

\subsection{Data Collection Process}

Ethical approval for this study was obtained from the Social and Humanities Ethics Committee of Van Yüzüncü Yıl University (number/id), the necessary official permission was granted by the District National Education Directorate, and the participating students and their families gave written informed consent. Prior to the start of the study, the height and bodyweight of 500 secondary school students were measured and body mass index (BMI) was determined by inserting these numbers in the BMI formula $\left(\mathrm{BMI}=\right.$ weight/ height $\left.{ }^{2}\right)$. Based on the results of these calculations, students were categorized as obese or normal weight. The obese students were then randomly assigned to one of two groups: obese experimental $(n=25)$ and obese control $(n=25)$ groups. Twenty-five students identified as being of normal weight according to their BMI values comprised the normal control group. For the pre-test, the Obesity Awareness Questionnaire was administered to all three groups and pedometer measurements were recorded on three weekdays (Monday, Wednesday, and Friday, between 07:00 a.m. and 12:30 p.m.) and two weekend days (Saturday and Sunday, for the entire day). The study period lasted 8 weeks, with health-related instruction provided once a week and aerobic exercise activities performed three times a week. 
The aerobic exercise program, each session of which lasted 45-60 minutes, was implemented outside of the student's normal school hours. Obese control and normal control students did not receive any health-related instruction or participate in any physical activity program during the 8-week study period. The health-related instruction and aerobic exercise programs were conducted by trained physical education teachers. Post-test measurements of the participants were taken following the conclusion of the 8-week health-related instruction and aerobic exercise program. As with the pre-test, the post-test included students' Obesity Awareness Questionnaire responses and the pedometer measurements from three weekdays and two weekend days.

\subsection{Data Analysis}

Since some data obtained failed the normality test, the Wilcoxon signed-rank test was performed to determine whether statistically significant differences existed between the pre-test and post-test values for the three groups with respect to their obesity awareness total score as well as obesity awareness, nutrition awareness, and physical activity awareness subscale scores. When normality was verified, a paired-samples t-test was performed to compare the pre- and post-test physical activity scores for the three groups of students.

\section{Results}

Analysis of the results indicated significant differences between the pre- and post-test scores of students in the obese experimental group with respect to total obesity awareness $[z=-4.375, p=.001]$, obesity awareness subscale $[z=-2.299, p=.001]$, nutrition awareness $[z=-4.378, p=.001]$, and physical activity awareness $[z=-4.408, p=$ $.001]$. The findings revealed that aerobic exercise and wellness training on the part of students in the experimental resulted in statistically significant increases in the scores for total obesity awareness $\left(\overline{x_{\text {pre-ese }}}=40.3, S D_{\text {pre-tese }}=4.9 ; \overline{x_{\text {post }}-}\right.$

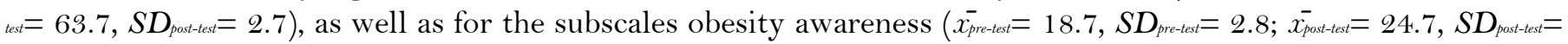

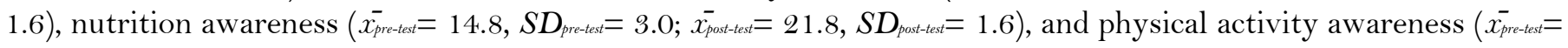

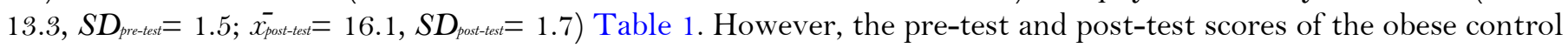
group did not change significantly in terms of either obesity awareness total $\left[z=-.517, p=.605,\left(\overline{x_{\text {pretes }}}=56.4, S D_{\text {pre- }}\right.\right.$

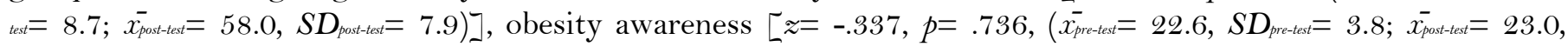

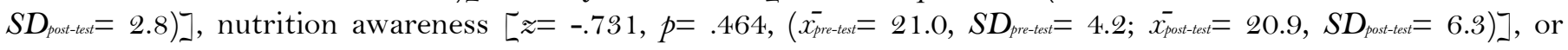
physical activity awareness $\left[z=-1.456, p=.145,\left(\overline{x_{\text {pretest }}}=12.0, S D_{\text {pre-test }}=2.4 ; \overline{x_{\text {post-est }}}=11.7, S D_{\text {post-tess }}=2.1\right)\right]$ Table 1. Similarly, there was no statistically significant difference between the pre-test and post-test results of the students in the normal control group with regard to the obesity awareness total $\left[z=-.787, p=.431,\left(\overline{p_{\text {pretess }}}=58.0, S D_{\text {pre-tes }}=6.3\right.\right.$;

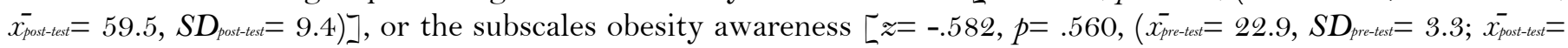

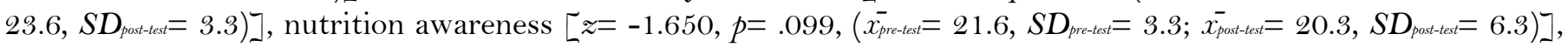

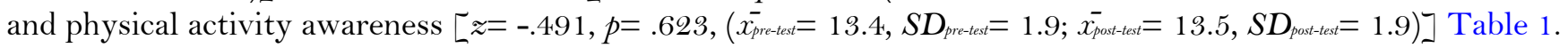

Table-1. Comparison of mean pre-test and post-test scores for the obesity awareness questionnaire.

\begin{tabular}{|c|c|c|c|c|c|c|}
\hline & & \multirow{2}{*}{$\mathbf{N}$} & Pre-test & Post-test & \multirow{2}{*}{$\mathbf{z}$} & \multirow[b]{2}{*}{$\mathbf{p}$} \\
\hline & & & $\left(\overline{x^{-} \pm S D}\right)$ & $(\overline{\mathbf{x}} \pm \mathbf{S D})$ & & \\
\hline \multirow{3}{*}{ Obesity awareness total score } & Obese Exp. & 25 & $40.3 \pm 4.9$ & $63.7 \pm 2.7$ & -4.375 & .001 \\
\hline & Obese Cont. & 25 & $56.4 \pm 8.7$ & $58.0 \pm 7.9$ & -.517 & .605 \\
\hline & Normal Cont. & 25 & $58.0 \pm 6.3$ & $59.5 \pm 9.4$ & -.787 & .431 \\
\hline \multirow{3}{*}{ Obesity awareness subscale score } & Obese Exp. & 25 & $18.7 \pm 2.8$ & $24.7 \pm 1.6$ & -4.299 & .001 \\
\hline & Obese Cont. & 25 & $22.6 \pm 3.8$ & $23.0 \pm 2.8$ & -.337 & .736 \\
\hline & Normal Cont. & 25 & $22.9 \pm 3.3$ & $23.6 \pm 3.3$ & -.582 & .560 \\
\hline \multirow{3}{*}{ Nutrition awareness score } & Obese Exp. & 25 & $14.8 \pm 3.0$ & $21.8 \pm 1.6$ & -4.378 & .001 \\
\hline & Obese Cont. & 25 & $21.0 \pm 4.2$ & $20.9 \pm 6.3$ & -.731 & .464 \\
\hline & Normal Cont. & 25 & $21.6 \pm 3.3$ & $20.3 \pm 3.3$ & -1.650 & .099 \\
\hline \multirow{3}{*}{ Physical activity awareness score } & Obese Exp. & 25 & $13.3 \pm 1.5$ & $16.1 \pm 1.7$ & -4.408 & .001 \\
\hline & Obese Cont. & 25 & $12.0 \pm 2.4$ & $11.7 \pm 2.1$ & -1.456 & .145 \\
\hline & Normal Cont. & 25 & $13.4 \pm 1.9$ & $13.5 \pm 1.9$ & -.491 & .623 \\
\hline
\end{tabular}

A paired samples $t$-test was applied to the data in order to determine whether a statistically significant difference existed between the pre-test and post-test physical activity levels of the students in the obese experimental, obese control, and normal control groups. An analysis of the results revealed significant differences between pre-test and post-test physical activity in the obese experimental group, $t(24)=-26.93, p=.001$. Those students, who received regular instruction in health-related knowledge and participated in an aerobic exercise program, substantially increased their weekday physical activity levels between the pre-test $(\bar{x}=5,748.76, S D=$ $478.85)$ and post-test $(\bar{x}=8,011.04, S D=515.02)$ period. Students in the obese control $\left[t(24)=-1.52, p=.14 ; \overline{p_{p r-t e x t}}=\right.$ $\left.5,483.04, S D_{\text {pre-tes }}=743.63 ; \overline{x_{\text {post-test }}}=5,840.60, S D_{\text {post-test }}=1,188.46\right]$ and normal control groups $\left[t(24)=1.70, p=.10 ; \overline{x_{\text {pre- }}}\right.$

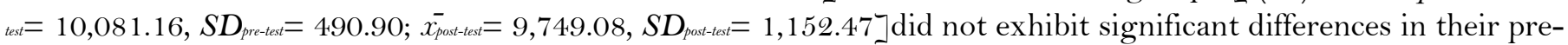
test and post-test physical activity levels Table 2. Weekend physical activity levels, meanwhile, did not significantly change from pre-test to post-test even for the obese experimental group $\left[t(24)=-.41, p=.69 ; \overline{p_{p r-t e s t}}=\right.$ $\left.11,140.64, S D_{\text {pre-tes }}=8,405.63 ; \overline{p o s i t-k s}=11,810.44, S D_{\text {post-test }}=748.32\right]$. Similarly, no significant differences between preand post-test weekend activity values were obtained for the obese control $\left[t(24)=1.17, p=.25 ; \overline{x_{p r e-t e s}}=10,066.08\right.$,

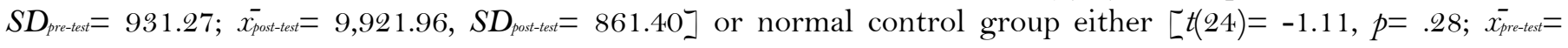

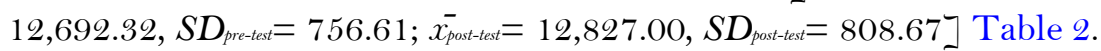


Table-2. Comparison of mean pre-test and post-test mean scores for weekday and weekend physical activity levels.

\begin{tabular}{|c|c|c|c|c|c|c|}
\hline & & \multirow{2}{*}{$\mathbf{N}$} & Pre-test & Post-test & \multirow{2}{*}{$\mathbf{t}$} & \multirow[b]{2}{*}{$\mathbf{p}$} \\
\hline & & & $(\bar{x} \pm \mathrm{SD})$ & $\left(\overline{x^{-}} \pm \mathrm{SD}\right)$ & & \\
\hline \multirow{3}{*}{ Weekday physical activity } & Obese Exp. & 25 & $5,748.76 \pm 478.85$ & $8,011.04 \pm 515.02$ & -26.93 & .001 \\
\hline & Obese Cont. & 25 & $5,483.04 \pm 743.63$ & $5,840.60 \pm 1,188.46$ & -1.52 & .14 \\
\hline & Normal Cont. & 25 & $10,081.16 \pm 490.90$ & $9,749.08 \pm 1,152.47$ & 1.70 & .10 \\
\hline \multirow{3}{*}{ Weekend physical activity } & Obese Exp. & 25 & $11,140.64 \pm 8,405.63$ & $11,810.44 \pm 748.32$ & -.41 & .69 \\
\hline & Obese Cont. & 25 & $10,066.08 \pm 931.27$ & $9,921.96 \pm 861.40$ & 1.17 & .25 \\
\hline & Normal Cont. & 25 & $12,692.32 \pm 756.61$ & $12,827.00 \pm 808.67$ & -1.11 & .28 \\
\hline
\end{tabular}

\section{Discussion}

The findings obtained in this study showed that instruction in health-related knowledge and aerobic exercise had positive effects on the obesity awareness and physical activity levels of lower secondary school students in the obese experimental group. Yesilfidan (2016) also examined the effects of health-related education on the health behaviors of adolescents at risk of obesity, finding that the instruction received by the 78 female and male participants led to an increase in healthy lifestyle behaviors and physical activity. Brown and Summerbell (2009) conducted a review study investigating the effects of diet and physical activity on the prevention of obesity in children and adolescents and reported that a healthy diet and physical activity were effective in preventing obesity in children between the ages of 0-5. Physical activity was also effective in preventing obesity in children between the ages of 6-12 and adolescents aged 13-18 years. Sevinç et al. (2011) administered nutrition and physical activity programs to Turkish primary school students and compared the BMI measurements of the participants. The researchers found that students included in both programs and those in only the nutrition program showed more improvement in terms of BMI compared to the control group, concluding that such programs may be effective in the prevention of childhood obesity. In a Norwegian study, Sola, Brekke, and Brekke (2010) implemented a 40week program, which included advice on healthy lifestyles and physical training, for obese children aged 6-14 years and their families. Their findings demonstrated that this program had a positive effect on the cardiovascular capacity, physical fitness, and BMI levels of obese children. Sigmund, El Ansari, and Sigmundová (2012) examined whether school-based physical activity practices were effective in preventing overweight and obesity in children aged 6-9 years. They reported that the students who participated in the school-based physical activity program were more active than the students who did not participate in the program. The researchers also revealed that the program led to an increase in the physical activity levels of students not only on school days but also on weekends. In another study, Carlin, Murphy, and Gallagher (2016) analyzed the results of 12 studies to determine whether the various programs had an impact on the walking activity of school children and adolescents; the findings of nine of these studies revealed that the programs implemented increased the amount of walking undertaken by the participants. The study also emphasized that goal orientation, planning, feedback and observation, social support, and the number of repetitions had an impact on this increase in walking.

Upon examination of the average daily number of steps obtained in this study, we observed an increase in the number of steps taken post-test by the students in the obese experimental group, who not only received healthrelated education but also participated in an aerobic exercise program. However, this number is remarkable in that it is less than the average number of steps recommended in the literature. We also noted that the number of steps taken by the students in the normal weight group was already close to the recommended number of steps and that the number of steps taken by the obese control group was below the recommended level, with no increase after 8 weeks. For adolescents, the recommended number of steps, based on the literature, varies between 10,000-11,700 daily (Tudor-Locke et al., 2011). Beets et al. (2010) examining 43 studies conducted in 13 countries involving the daily step counts of adolescents, revealed that their physical activity levels varied by country. They also found that young people's cardiovascular fitness levels are decreasing while obesity is increasing. Researchers have shown that physical inactivity is more widespread in countries where people tend to cover short distances by car, especially the U.S., while inactivity is less common in countries where activities such as walking and cycling are popular. The existence of opportunities for adolescents to engage in physical activity during school hours as well as outside of school was also found to impact physical activity levels. These results supported our finding that the physical activity levels of obese adolescents increased when given the opportunity to engage in an aerobic exercise program. In a study conducted in New Zealand, Hohepa, Schofield, Kolt, Scragg, and Garrett (2008) examined the factors affecting the physical activity of students aged 12-18 as determined by pedometer use, finding that adolescents in New Zealand were less active than their peers in other countries. The researchers also observed that male adolescents were more active than female adolescents and that those of the younger age were more active than older adolescents. The number of steps taken by the study participants during the week was found to be higher than the number of steps taken on the weekend, and adolescents who walked to school were, unsurprisingly, more active than those who went by bus or car. The reason for the low physical activity levels of adolescents in the present study, especially of those in the obese control group, both before and after the intervention, may be due to the fact that the participants had to use vehicles to travel to school and may not have had the sufficient opportunity to engage in extra physical activities.

Low levels of physical activity among adolescents constitute a serious problem not only in Turkey, but globally as well. The physical activity levels of Swedish adolescents with an average age of 12.7 were measured by pedometer in 2000, 2003, and 2005, with the findings revealing only low to moderate levels of physical activity. Troiano et al. (2008) examined the physical activity levels of children, adolescents, and adults in the U.S. and found that men were more active than women and that physical activity decreased with age. They also reported that $42 \%$ of the children in the 6-11 age groups had attained the recommended level of physical activity, but that this rate decreased to only $8 \%$ in adolescents. Richardson et al. (2008) investigated the effects of pedometer-based interventions on weight loss in a meta-analysis, concluding that interventions using a pedometer showed a modest effect on weight loss but that the effect should increase if the interventions are prolonged. Studying the contribution of pedometer use to an increase in physical activity, Bravata et al. (2007) showed results consistent 
with those of other studies, reporting that the use of pedometer increased the level of physical activity while decreasing BMI and blood pressure. In another meta-analysis study, Kang, Marshall, Barreira, and Lee (2009) found that pedometer use in intervention studies had a moderate effect on increasing physical activity and that more benefits resulted when the participants aimed to reach a certain number of steps. These findings are consistent with those of this study, which also employed pedometers to record step counts.

The findings obtained in the present study revealed that health-related knowledge provided to obese adolescents increased their levels of obesity awareness, nutrition awareness, and physical activity awareness. In a similar study, Kucuk, Avşar, Akın, and Pınar (2019) examined the effects of educating adolescents regarding healthy lifestyle habits on their perceptions of the causes, risks, and negative consequences of obesity. The researchers revealed that the instruction received by the adolescents led to positive changes in their perceptions of the negative consequences of obesity and their responsibility to combat it. Nicholls et al. (2014) meanwhile, investigated the effects of a three-year program involving an active lifestyle and healthy diet habits for children and found that the program contributed to the prevention of obesity in children. In a Turkish study, Ekici and Yıldız (2018) examined the effects of a nutrition management program on weight control, nutritional attitudes, and physical activity in adolescents. While the program, which was administered to students aged 11-12, did not result in any significant difference in terms of attitudes toward a healthy diet and physical activity in the experimental and control groups, the mean body weight of adolescents in the experimental group did show a decrease. In an experimental study, $\mathrm{Oz}$ (2015) designed and implemented an internet-based nutritional education program for high school students in order to promote the adoption of healthy eating habits, to improve physical activity levels, and to decrease sedentary behaviors. Results indicated that the students who were involved in the nutritional program increased their knowledge of healthy lifestyle behaviors as well as their physical activity levels and that their number of steps reached the recommended daily level. In another study conducted in Turkey, Erdim (2012) examined the effects of a diet and exercise program designed for obese children and their families on their diet, exercise habits, and BMI. The researcher reported that the diet and exercise program reduced primary school children's sedentary behaviors, increased their physical activity levels, and lowered their BMI. Furthermore, as a result of educating the families of the obese children, they decreased the number of unhealthy foods in their homes. As revealed in the current study, related literature also suggests that instructing adolescents in healthy lifestyle habits, nutrition, and physical activity affects their attitudes and behaviors with regard to obesity, healthy diets, and physical activity.

In conclusion, the present study has revealed that health-related knowledge and aerobic exercise increased the obesity awareness and physical activity levels of female students at the lower secondary school level. Based on these findings, we recommend that programs aimed at increasing the physical activity levels of adolescents and preventing obesity should be incorporated in the educational curriculum at the national level.

\section{References}

Akyol, B., Boyraz, M., \& Aysoy, C. (2013). Relationship of epicardial adipose tissue thickness with early indicators of atherosclerosis and cardiac functional changes in obese adolescents with metabolic syndrome. Journal of Clinical research in Pediatric Endocrinology, 5(3), 156-163.Available at: https://doi.org/10.4274/jcrpe.1064.

Allen, A. (2011). Effects of educational intervention on children's knowledge of obesity risk factors. Unpublished Dissertation. US: Carrol College.

Beets, M. W., Bornstein, D., Beighle, A., Cardinal, B. J., \& Morgan, C. F. (2010). Pedometer-measured physical activity patterns of youth: A 13-country review. American Journal of Preventive Medicine, 38(2), 208-216.Available at: https://doi.org/10.1016/j.amepre.2009.09.045.

Bilgin, E., Bulca, Y., \& Demirhan, G. (2020). Examining the relationship between physical activity level, physical fitness, academic achievement and the concept of academic self. Education and Science, 45(202), 311-325.

Bravata, D. M., Smith-Spangler, C., Sundaram, V., Gienger, A. L., Lin, N., Lewis, R., \& Sirard, J. R. (2007). Using pedometers to increase physical activity and improve health: A systematic review. Jama, 298(19), 2296-2304.Available at: https://doi.org/10.1001/jama.298.19.2296.

Brown, T., \& Summerbell, C. (2009). Systematic review of school-based interventions that focus on changing dietary intake and physical activity levels to prevent childhood obesity: An update to the obesity guidance produced by the National Institute for Health and Clinical Excellence. Obesity Reviews, 1O(1), 1 10-141.Available at: https://doi.org/10.1111/j.1467-789X.2008.00515.x.

Can, S. (2019). Physical activity measurement: Objective and subjective methods. Journal of Sports Medicine, 54(4), $296-307$.

Carlin, A., Murphy, M. H., \& Gallagher, A. M. (2016). Do interventions to increase walking work? A systematic review of interventions in children and adolescents. Sports Medicine, 46(4), 515-530.Available at: https://doi.org/10.1007/s40279-015-0432-6.

Collins, C. E., Okely, A. D., Morgan, P. J., Jones, R. A., Burrows, T. L., Cliff, D. P., \& Baur, L. A. (2011). Parent diet modification, child activity, or both in obese children: An RCT. Pediatrics, 127(4), 619-627.Available at: https://doi.org/10.1542/peds.2010-1518d.

Demirci, N. (2017). Investigating of step count school time and out of school time in 11-13 aged children engaged in outdoor sports activity. Unpublished Masters Thesis. Hacettepe University, Institute of Health Sciences, Ankara.

Ekici, E., \& Yıldız, A. (2018). Weight management effects of adolescents 5210 nutrition management program. Turkey Diabetes and Obesity Journal, 2(2), 72-84.Available at: https://dergipark.org.tr/en/pub/tudod/issue/39034/456558.

Erdim, L. (2012). The influences of a feeding and exercise program for overweight children. Unpublished PhD Dissertation. Marmara University. Institute of Health Sciences.

Guinhouya, B., Samouda, H., \& De Beaufort, C. (2013). Level of physical activity among children and adolescents in Europe: A review of physical activity assessed objectively by accelerometry. Public Health, 127(4), 301-311.Available at: https://doi.org/10.1016/j.puhe.2013.01.020.

Guthold, R., Stevens, G. A., Riley, L. M., \& Bull, F. C. (2020). Global trends in insufficient physical activity among adolescents: A pooled analysis of 298 population-based surveys with 1.6 million participants. The Lancet Child \& Adolescent Health, 4(1), 23-35.Available at: https://doi.org/10.1016/s2352-4642(19)30323-2.

Hohepa, M., Schofield, G., Kolt, G. S., Scragg, R., \& Garrett, N. (2008). Pedometer-determined physical activity levels of adolescents: Differences by age, sex, time of week, and transportation mode to school. Journal of Physical Activity and Health, 5(s1), S140S152.Available at: https://doi.org/10.1123/jpah.5.s1.s140.

Jurakic, D., \& Pedisic, Z. (2012). Prevalence of insufficient physical activity in children and adolescents. Paediatria Croatica, 56(4), $321-326$.

Kafkas, M., \& Ozen, G. (2014). The Turkish validation of the obesity awareness scale: A validity and reliability study. Journal of Physical Education and Sport Sciences, 1(2), 1-15.

Kang, M., Marshall, S. J., Barreira, T. V., \& Lee, J.-O. (2009). Effect of pedometer-based physical activity interventions: A meta-analysis. Research Quarterly for Exercise and Sport, 80(3), 648-655.Available at: https://doi.org/10.5641/027013609x 13088500160000.

Katz, D. L., O'Connell, M., Njike, V. Y., Yeh, M.-C., \& Nawaz, H. (2008). Strategies for the prevention and control of obesity in the school setting: Systematic review and meta-analysis. International Journal of Obesity, 32(12), 1780-1789.Available at: https://doi.org/10.1038/ijo.2008.158. 
Kucuk, Y. M., Avşar, P., Akın, E. A., \& Pınar, S. (2019). Educational interventions to change obesity perceptions among high school students. Journal of Sports Medicine, 54(Supp 1), 28-39.Available at: https://doi.org/10.5152/tjsm.2019.149.

Kudaş, S., Ulkar, B., Erdoğan, A., \& Cirçı, E. (2005). Physical activity and some eating habits of 11-12 age group children in Ankara. Hacettepe Journal of Sports Sciences, 16(1), 19-29.

Nicholls, L., Lewis, A. J., Petersen, S., Swinburn, B., Moodie, M., \& Millar, L. (2014). Parental encouragement of healthy behaviors: Adolescent weight status and health-related quality of life. BMC Public Health, 14(1), 1-8.Available at: https://doi.org/10.1186/1471-2458-14-369.

Oz, F. (2015). Evaluation of the effectiveness of internet based nutrition education programme in adolescents: A randomized controlled trial. Unpublished Masters Thesis. Eskişehir Osmangazi University. Institute of Healh Sciences.

Ozturk, A., Mazicioglu, M., Poyrazoglu, S., Cicek, B., Gunay, O., \& Kurtoglu, S. (2009). The relationship between sleep duration and obesity in Turkish children and adolescents. Acta Paediatrica, 98(4), 699-702.Available at: https://doi.org/10.1111/j.16512227.2008.01169.x

Raustorp, A., \& Fröberg, A. (2018). Tracking of pedometer-determined physical activity: A 16-year follow-up study. Journal of Physical Activity and Health, 15(1), 7-12.Available at: https://doi.org/10.1123/jpah.2017-0146.

Richardson, C. R., Newton, T. L., Abraham, J. J., Sen, A., Jimbo, M., \& Swartz, A. M. (2008). A meta-analysis of pedometer-based walking interventions and weight loss. The Annals of Family Medicine, 6(1), 69-77.Available at: https://doi.org/10.1370/afm.761.

Saygın, Ö., \& Bayrakdar, A. (2012). Evaluation of body mass index and basal metabolic rate, step number of days in boys children. Journal of Human Sciences, 9(1), 372-384.

Saygin, O., \& Ceylan, H. İ. (2017). Comparison of middle school and high school students' body mass index with the number of daily steps by age and gender. International Journal of Sport, Exercise \& Training Sciences, 3(4), 142-152.Available at: https://doi.org/10.18826/useeabd.337683.

Sevinç, Ö., Bozkurt, A. İ., Gündoğdu, M., Aslan, Ü. B., Ağbuğa, B., Aslan, Ş., \& Gökçe, Z. (2011). Evaluation of the effectiveness of an intervention program on preventing childhood obesity in Denizli, Turkey. Turkish Journal of Medical Sciences, 41(6), $1097-1105$.

Sigmund, E., El Ansari, W., \& Sigmundová, D. (2012). Does school-based physical activity decrease overweight and obesity in children aged 6-9 years? A two-year non-randomized longitudinal intervention study in the Czech Republic. BMC Public Health, 12(1), 113.Available at: https://doi.org/10.1186/1471-2458-12-570.

Sola, K., Brekke, N., \& Brekke, M. (2010). An activity-based intervention for obese and physically inactive children organized in primary care: Feasibility and impact on fitness and BMI: A one-year follow-up study. Scandinavian Journal of Primary Health Care, 28(4), 199204.Available at: https://doi.org/10.3109/02813432.2010.514136.

Troiano, R. P., Berrigan, D., Dodd, K. W., Masse, L. C., Tilert, T., \& McDowell, M. (2008). Physical activity in the United States measured by accelerometer. Medicine $\&$ Science in Sports $\mathcal{E}^{\circ}$ Exercise, 40(1), 181-188.Available at: https://doi.org/10.1249/mss.obo13e31817057da.

Tudor-Locke, C., Craig, C. L., Beets, M. W., Belton, S., Cardon, G. M., Duncan, S., \& Raustorp, A. (2011). How many steps/day are enough? for children and adolescents. International Journal of Behavioral Nutrition and Physical Activity, 8(1), 1-14.Available at: https://doi.org/10.1186/1479-5868-8-78.

Tunç, E., \& Işler, A. K. (2007). Examining the physical activity level of high school and university students according to age and gender. Gazi Journal of Physical Education and Sports Sciences, 12(2), 11-18.

Turkish Ministry of Health. (2011). Turkey in the school age children (6-10 age group) growth monitoring (TOÇB) project research report. General Directorate of Primary Health Care Ankara: Ministry of Health Publication No: 834.

Urlu, Y. (2014). Analyzing physical activity levels of the children between 10-12 age group (Antalya example). Unpublished PhD Dissertation. University of Balıkesir.

World Health Organization (WHO). (2020a). Obesity and overweight: Key facts. Retrieved from https://www.who.int/news-room/factsheets/detail/obesity-and-overweight.

World Health Organization (WHO). (2020b). Global health observatory (GHO) data:Prevalence of insufficient physical activity. Retrieved from https://www.who.int/gho/ncd/risk_factors/physical_activity_text/en/.

World Health Organization (WHO). (2020c). Global strategy on diet, physical activity and health: Physical activity and young people. Retrieved from: https://www.who.int/dietphysicalactivity/factsheet_young_people/en.

Yesilfidan, D. (2016). The effect of education on developing positive health behaviors given to adolescents at risk of obesity on healthy lifestyle behaviors and physical activity. Unpublished Master's Thesis. Adnan Menderes University, Institute of Health Sciences. 